\title{
Manierismus als Selbstbehauptung: Jean Paul
}

\section{Wolfgang Braungart}

Wolfgang Braungart (geb. 1956) ist seit 1996 Professor für neuere deutsche Literatur und allgemeine
Literaturwissenschaft an der Universität Bielefeld. Seine Forschungsschwerpunkte sind: Literatur in ihrem
Verhältnis zur Kunstgeschichte und zur populären Kultur, Literatur und Religion, Literaturanthropologie,
literarische Utopie sowie Literaturgeschichte der frühen Neuzeit und die Literatur der letzten Jahrhundertwende.

Jean Pauls stilistische Eigenarten sind augenfällig und auch oft beschrieben worden. Sie sind der Grund dafür, daß er - seinerzeit viel gelesen, wenngleich doch nicht wirklich ein Erfolgsschriftsteller - heute unter den herausragenden Autoren der Zeit um 1800 der wohl unbekannteste ist. Jean Paul gilt nicht nur als ein schwieriger Autor. Er ist es tatsächlich auch.

Rüdiger Zymner hat jüngst in seinem aus literaturwissenschaftlicher Sicht grundlegenden ManierismusBuch für diese sManier / Jean Pauls energisch noch einmal den Manierismus-Begriff in Anspruch genommen und dabei besonders Formenreichtum, Komplexität (vor allem das Spiel mit Eigentlichkeit und Uneigentlichkeit, das Spiel mit Fiktion und Wirklichkeit), Dunkelheit und Schwierigkeit (im Bereich der Lexik, in der demonstrativen Gelehrsamkeit) hervorgehoben. Dabei stellt er besonders einen Zusammenhang zwischen Humor und Manierismus her und charakterisiert Jean Pauls Manierismus als eine besonders subjektiv erscheinende Schreibweise. Jean Paul finde »mit seiner Verbindung von Humor und Manierismus doch so etwas wie einen dritten_Weg zwischen den Konzeptionen der Klassik und der Romantik als Antwort auf die Frage nach Bedingungen und Möglichkeiten zeitgenössischer Dichtkunst. « (1) Für Zymner also ist Manierismus bei Jean Paul - ich bleibe im philosophisch-ästhetischen Diskurs der Zeit um 1800 - eine transzendentalpoetische Kategorie. Sie bedeutet eine permanente Reflexion über Poesie im Medium der Poesie selbst. Meine Überlegungen knüpfen an Zymner an und versuchen nur, den Akzent ein wenig vom Transzendentalpoetischen in die Pragmatik des Ästhetischen zu verschieben. Denn grundsätzlich ist das manierierte Kunstwerk Ergebnis einer >manierierten ‘ künstlerischen Handlung. Darauf weist schon die Etymologie hin: Manierismus kommt von Manier. Manier (maniera) meint seit der Renaissance - und zunächst ohne kritische Nebenbedeutung - die besondere Eigenart und Gestaltungsweise eines Künstlers, seine individuelle •Handschrift ‘, die ihn charakterisiert und also von anderen Künstlern unterscheidet. Damit wird aus einer ästhetischen Kategorie eine soziale. Auf dieses Moment deutet auch die alltagssprachliche Verwendung von >Manier ‘ hin. (Wir sagen z. B., jemand benehme und verhalte sich manieriert.) Am Manierismus läßt sich also exemplarisch untersuchen, wie ästhetische Kategorien als soziale und soziale Kategorien als ästhetische reformuliert werden können. (2) Seine selberlebensbeschreibung (im Titel schon eine Demonstration von Gelehrsamkeit: nämlich die Übersetzung von griech. >Autobiographie`) machte Jean Paul solche Mühe, weil er, wie er schon in einem Brief 1818 sagt, »durch die Romane so sehr ans Lügen gewöhnt « sei, daß er »zehnmal lieber jedes andere [Leben] beschriebe « (3) als sein eigenes. Er beginnt die Selberlebensbeschreibung mit dem folgenden, charakteristischen Satz:

Es war im Jahr 1763, wo der Hubertsburger Friede zur Welt kam [Ende des Siebenjährigen Krieges; Friedensverträge zwischen Preußen, Österreich und Sachsen] und gegenwärtiger Professor der Geschichte von sich; - und zwar in dem Monate, wo mit inm noch die gelbe und graue Bachstelze, das Rotkehlchen, der Kranich, der Rohrammer und mehre Schnepfen und Sumpfvögel anlangten, nämlich im März; - und zwar an dem Monattage, wo, falls Blüten auf seine Wiege zu streuen waren, gerade dazu das Scharbock- oder Löffelkraut und die Zitterpappel in Blüte traten, desgleichen der Ackerehrenpreis oder Hühnerbißdarm, nämlich am 21ten März; - und zwar in der frühesten frischesten Tagzeit, nämlich am Morgen um 1 1/2 Uhr; was aber alles krönt, war, daß der Anfang seines Lebens zugleich der des damaligen Lenzes war. (4)

Das Zitat zeigt eindrucksvoll Jean Pauls Lust an der Abschweifung und am >Metaphorisieren<, an einem mäandrierenden Stil. Aber doch auch noch mehr: Politischer Frühling, Anbruch eines Lebens und Frühling im Jahreszeitenzyklus; Individualbiographie, politisches Ereignis und Naturgeschehen werden in einen Bezug gebracht. Mit unverkennbarer Sprachlust werden die Namen der Tiere und Pflanzen aufgezählt: "Scharbock- oder Löffelkraut« und »Hühnerbißdarm«, d. i. vermutlich übrigens die Vogelmiere (auch: Hühnerdarm), die man in der Oberpfalz Kindern in die Wiege legt. (5) Die Namen entbehren nicht einer gewissen sprachlich-ästhetischen Skurrilität, die also von Beginn an zu diesem Lebensfrühling gehört. Zum Rotkehlchen gehören auch die Schnepfen- und Sumpfvögel, zu der Bachstelze der Kranich, dessen Name sich so ausspricht, wie er schreit. Das Disparate und bis in die 
Namen hinein Individuelle wird nicht harmonisiert, sondern nur zusammengezogen zu einem sprechenden poetischen Bild, einer Allegorie des Frühlings, die aber die Individualität nicht aufhebt. Vielleicht ist es ein wenig weit hergeholt, wenn ich dabei auch an die berühmten Bilder Arcimboldos denke, in dessen Jahreszeiten-Allegorien die Einheit nicht um den Preis der Aufhebung des Individuellen zustande kommt. Sie wollen nicht den Eindruck eines harmonischen Ganzen erwecken (Abb. 1). Ähnlich könnte man für die naturkundlichen Darstellungen Georg Hoefnagels argumentieren (Abb. 2).

Sprachliche Mäander und Digressionen sind bei Jean Paul ein konstitutives ästhetisches Prinzip, das als solches zugleich immer auf den Leser hin reflektiert und so potenziert wird: »Den letzten Einfall«, so Jean Paul weiter, „hab' ich in Gesprächen wohl schon hundert Male vorgebracht; aber ich brenn' ihn hier absichtlich wie einen Ehrenkanonenschuß zum 101ten Male ab, bloß damit ich mich durch den Abdruck außer Stand setze, einen durch den Preßbengel [also durch den »Hebel zum Festziehen der Schraube an der Buchbinderpresse «(6) schon an die ganze Welt herumgereichten Bonmot-Bonbon von neuem aufzutragen. «(7) Etwas einfacher: Jean Paul will sich selbst durch die Veröffentlichung dieses Einfalls daran hindern, eben diesen Einfall immer wieder zu erzählen. Diese selbstreflexive Begründung der Abschweifung ist selbst eine Abschweifung.

Diese gezeigte, inszenierte Selbstbezüglichkeit, in der die erzählerischen Verfahren als solche förmlich thematisch werden und die Aufmerksamkeit des Lesers entsprechend gelenkt wird, ist ein verbindendes Prinzip des Manierismus in der Bildenden Kunst, in der Literatur - und, in analoger Weise (Thematisierung von Kleidung als Kleidung, von Gesten als Gesten usw.), im sozialen Leben. Zugleich kann gerade dadurch eine neue symbolische Bedeutung freigesetzt werden.

Ein besonders schönes Beispiel für eine solche mäandrierende und sich inszenierende Selbstreflexivität ist die 'Geschichte meiner Vorrede zur zweiten Auflage des Quintus Fixleink. Die Konventionalität der üblichen Initiation in den Text durch Einleitung oder Vorwort wird dadurch durchbrochen, daß diese Initiation selbst thematisiert wird. Das ist auch im sozialen Leben eine Möglichkeit, Konventionen und Rituale mit neuer Bedeutung aufzuladen. Man kann innen auf reflexive Weise Genüge tun und also doch ihr Recht lassen, ohne sich an sie auszuliefern. So wird eine solche reflexive Inszenierung eines Rituals oder einer Konvention zugleich zu einer Inszenierung der Freiheit des Individuums in diesem Akt der Bestätigung einer sozialen Verhaltensnorm selbst.

Aber noch einmal kurz zum zitierten Beginn der `Selberlebensbeschreibung z zurück: Das erzählerische Prinzip ist genau das des Erzählens von Einfällen. Die Einfälle - er »heckte [...] täglich die neuen Einfälle zu Schocken « (8) müssen freilich heraus; sie lassen sich nicht einfach unterdrücken. Der Autorwille ordnet und organisiert dabei aber nicht sichtbar. Oder in den Worten einer Gründungsschrift des deutschen Klassizismus, der Schillerschen Rezension der Gedichte Bürgers von 1791: Der Autor läutert sich hier nicht hinauf zur höheren Menschheit; er veredelt nicht das Höchste, was er zu geben im Stande ist: seine »Individualität«. (9) Und zwar nicht, weil er nicht kann, sondern weil er nicht will. Er stellt damit seine Autor-Subjektivität förmlich zur Schau. Darin liegt das - sozial und ästhetisch - Provokative von Jean Pauls Schreibweise.

Kann man Schillers ästhetische Kategorien in stilistischer Hinsicht als eine klassizistische Anknüpfung an rhetorischen Attizismus lesen, an rhetorische Zucht und Disziplin (die Schiller Bürger gerade abspricht), an claritas und perspicuitas, so Jean Pauls ästhetisches Verfahren als dezidierte, reflektierte Verweigerung eben solcher Stilprinzipien, die bei Schiller zugleich ethische Prinzipien implizieren. Oder, mit dem Gegenbegriff: als ästhetischen Asianismus. Eine ethische Komponente hatte die Kritik übertriebenen sprachlichen Prunkes gewiß auch schon in der Antike, so bei Cicero. Sie wurde aber nicht mit einer grundlegenden kulturkritischen Perspektive verbunden. (10) (Für die griechische Antike - Platon - läßt sich dies freilich nicht so entschieden sagen.) Sobald Stil aber in der Neuzeit als Ausdruck des Zustandes einer Kultur verstanden wird - in der deutschen Literaturgeschichte frühestens seit der allmählichen Auflösung des rhetorischen Textmodells, der Auflösung des Zusammenhangs von Stil und Rhetorik, einsetzend mit der Schwulstkritik seit dem ersten Drittel des 18. Jahrhunderts (11), wird Stilkritik zur Kulturkritik. (12) Das bekommt der künstlerische Manierismus zu spüren. Der Begriff ist bis heute in den Geistes- und Kulturwissenschaften umstritten. Er impliziert häufig eine kulturkritische Perspektive und gehört dann in ein System eingespielter kultureller Dichotomien (natürlich vs. künstlich, klassisch vs. romantisch, Aufstieg und Blüte vs. Verfall; am deutlichsten: gesund vs. krank).

Diesen Zusammenhang zwischen Stil und Kulturkritik gibt es auch bei Jean Paul. Ich komme darauf gleich noch einmal zurück. Jean Pauls spezifische Schreibweise sollte man jedoch nicht bloß als Spielraum individualistischer >Narrenfreiheit verstehen - und auch er selbst versteht sie gerade nicht so -, sondern als ästhetische sSelbstbehauptung<. (13) Sie bedeutet mehr als nur ästhetische Modernität durch intertextuelle Vielstimmigkeit, die Jean Paul freilich mit geradezu demonstrativer Lust instrumentiert. (14) 
In der Vorrede zur zweiten Auflage des Hesperus $\left(1795 ;{ }^{2} 1798\right)$ verteidigt Jean Paul ausdrücklich seine ,Manier «: Sprachliche Schwächen und Fehler habe er korrigiert; »die Einfälle aber und die poetischen Tulpen hab' ich selten ausgerissen «, weil sie für seinen Roman essentiell sind: »Ich sah, wenn ichs täte, so bliebe vom Buche (weil ich die ganze Manier ausstriche) nicht viel mehr in der Welt als der Einband und das Druckfehler-Verzeichnis. «(15) Hier wird der Zusammenhang von Manier und Manierismus überdeutlich. Jean Pauls manieristische Manier ist für ihn selbst viel mehr als undisziplinierte stilistische Formlosigkeit und insofern auch ethisch problematische Unbeherrschtheit: An ihr und durch sie definiert er sich als Autor, und zwar gerade in Abgrenzung zu anderen Autoren. Sie ist Zentrum seines Schreibens. Darum kann er in dieser Vorrede auch energisch die Architektur seines Romans betonen, die es nicht dulde, daß man »aus dem ersten Stockwerk (oder Heftlein) nur irgendeinen brüchigen Quader ausziehe«, weil sonst »sofort im dritten alles wackelt und herausfällı«. (16) Ich möchte nur daran erinnern, wie wichtig die Architektur- und Gebäudemetapher in der Geschichte des abendländischen Denkens ist. Sie ist z. B. eine Schlüsselmetapher für den philosophischen Rationalismus von Descartes, grundsätzlich für Ordnung und Strukturiertheit. Zur Ikonographie der Wissenschaften gehört es auch, sie in einem Gebäude darzustellen. Wenn Jean Paul diese Metapher aufnimmt, dann heißt das auch: da will sich einer nicht bloß in hemmungsloser Sprachlust ergehen.

Wie ernst es Jean Paul mit dieser Metapher ist, sieht man daran, daß er ironisch sein eigenes Werk weit hinter die »neuen Romane « zurücksetzt, die »nicht, wie mein Buch, einem bloßen Haus, sondern einer ganzen Spielstadt aus Nürnberg gleichen«, bei dem die einzelnen Elemente ganz nach Belieben variiert, neu zusammengesetzt, aber auch ohne jedes weitere System aufeinander gestapelt werden können. (17) Sein Roman ist also nicht mit dem Nürnberger Blechspielzeug zu vergleichen; sein Manierismus ist kein bloß selbstzweckhaftes ästhetisches Spiel. Es geht also gerade nicht um Autonomisierung der ästhetischen Mittel, sondern um ästhetische Positionsfindung und Selbstbehauptung gegen die Herausforderungen aus Weimar, Jena und Berlin.

Die junge romantische Literatur um 1800 bringt eine Reihe ästhetischer Formen und Redestrategien hervor - Fragment, Ironie, Arabeske, Auflösung der poetischen Gattungsgrenzen, Verwischung der Grenzen zwischen expositorischen und poetischen Texten -, die sich in der Gruppe der Frühromantiker auch als ästhetische Selbstdarstellungen und Positionsfindungen begreifen lassen. Im Fragment z. B. kann man auch eine Form rascher, geistreicher Zuspitzung sehen, die auf andere geistreiche Zuspitzungen - sowohl die eigenen wie die der Gruppenmitglieder - Bezug nimmt und sie überbietet. Der Prozeß der Gruppenbildung in der Frühromantik ist insofern auch ein ästhetischer Prozeß. Die Gruppe stellt sich als solche in ihren poetisch-philosophischen Äußerungen dar und ordnet sich sozial durch sie. Zur Diskussion steht hier also nicht primär ein theoretisches Konzept im Sinne einer philosophischen Ästhetik, sondern die ästhetischen Phänomene in ihrem sozialen Zusammenhang. Aus diesem läßt er sich aber nicht einfach ableiten; denn der soziale Zusammenhang konstituiert sich entschieden ästhetisch. Man kann aber, das soll nur am Rande vermerkt sein, die Bedeutung der in der Romantik favorisierten Formen mit solchen Konzepten in Beziehung setzen. In der Vorschule der Ästhetik entwirft Jean Paul z. B. - gegen Kant und Schiller - ein Konzept des Erhabenen, dem das Lächerliche als konstitutives Komplement an die Seite gestellt ist und das deshalb auch eine Mischung der Gattungen und Formen - des Hohen und des Niederen, des Pathetischen und des Komischen - erfordert. (18) Ich fasse kurz zusammen: Seine eigene manieristische Schreibweise wird von Jean Paul also als solche durchaus gesehen und verteidigt. Sie grenzt ihn ab und schafft ihm Luft gegen den ästhetischen Führungsanspruch der Weimarer Klassik wie auch gegen die sich innovativ gebende, ihm in vielem ästhetisch besonders nahestehende Frühromantik, die er freilich selbst nicht ganz unkritisch kommentiert. (19) Das ließe sich an vielen Belegen etwa aus der Vorschule der Ästhetik zeigen, wenn Romantiker wie z. B. Novalis den poetischen Nihilisten zugerechnet werden, deren Innerlichkeit allen Weltbezug auflöse. Die ästhetische Selbstbehauptung wird bei Jean Paul im ästhetischen Diskurskontext der Zeit um 1800 zugleich und unvermeidlich auch zur sozialen Selbstbehauptung. Die Selberlebensbeschreibung legt von diesem konstitutiven sozialen Bezug seines Schreibens ein beredtes Zeugnis ab. So lese ich auch Jean Pauls selbstbewußte Kunst der Selbstverkleinerung: Er will keine Schule der Ästhetik vorlegen, sondern allenfalls eine Vorschule, durch die man freilich hindurch muß, sollte es denn je gelingen, in die Schule zu kommen (und Jean Paul läßt keinen Zweifel daran, daß die >Vorschule ‘ die eigentliche Schule ist). Die vermeintliche Willkür und Freiheit dieses Schreibens ist den Schwierigkeiten des eigenen Lebens abgerungen. (20)

Ich werde diese These jetzt noch kurz mit vier weiteren Überlegungen flankieren, die etwas präzisieren sollen, wie sich mir Jean Pauls Manierismus darstellt. 
1. Selbstbehauptung durch Eklektizismus und Synkretismus als Selbstbehauptung in den verschiedenen Diskursen von Kunst, Literatur, Philosophie, Theologie und moderner romantischer Naturwissenschaft um 1800.

In Anspielungen, Fußnoten, Parenthesen verwischt Jean Paul die Grenzen zwischen expositorischem und poetischem Text und inszeniert seine Gelehrsamkeit und Belesenheit als witzige und ironischgeistreiche Manier. Es geht dabei nicht primär um den standesbewußten Anspruch, zur res publica litteraria zu gehören wie etwa noch bei Lessing. Das Buch integriert bei Jean Paul einen ganzen gelesenen Kosmos. Das Buch ist die Kunstkammer, der Sammlungsraum, in dem sich die neue Subjektivität (als sich ihrer selbst bewußte Individualität) darstellt. Der Roman Jean Pauls ist eine Enzyklopädie, in denen ein Subjekt Ordnung schafft nach Prinzipien, die nur es selbst kennt und niemand sonst. Aber so wenig die frühneuzeitliche Kunstkammer nur Ausdruck einer krausen manieristischen Phantasie war, als die sie in der Forschung lange Zeit gegolten hat, sondern räumliches und konzeptionelles Integrationsprinzip aller Wissenschaften und Künste (s. Abb. 2), so wenig ist es Jean Pauls Roman.

Die manieristische Schreibweise hat bei Jean Paul auch diesen medienästhetischen Aspekt, wie sich oben schon in der Selberlebensbeschreibung gezeigt hat: nicht die Welt als Buch, sondern das Buch als Welt, in dem die Mineralia der Gelehrsamkeit und die Blumen der Poesie gesammelt werden. (21) Man braucht sich dazu nur die Zwischentitel z. B. der Flegeljahre anzuschauen, in denen Sprachlust und Sammellust zusammenkommen: Bleiglanz; Katzensilber; Terra Miraculosa Saxoniae; Mammutsknochen; Vogtländischer Marmor usw. Wie Differenzierung und Prozessualisierung von Kunst und Wissenschaft den barocken Sammlungsraum aufgelöst haben, so verlangt auch der Roman Jean Pauls die Prozeßualität der Welterschließung durch einen gutwilligen, mitgehenden Leser. Und deshalb werden eben doch auch sich entwickelnde Geschichten erzählt, nicht nur Welt im Buch beschrieben. Zu diesem Zusammenhang von Manierismus und Dialog mit dem Leser gleich noch etwas genauer. Mörike ist übrigens ein anderer, Jean Paul verwandter Autor, bei dem sich ebenfalls Sprachsammellust und grundsätzliches Angelegtsein aufs Gespräch und auf Geselligkeit verbinden, bei inm nun im Kontext der bürgerlichen Geselligkeitskultur des 19. Jahrhunderts.

Eklektizismus und Synkretismus sind, nach der Verabschiedung operativ-rhetorischer Modelle von Literatur und Kunst, konstitutiv für die Spätaufklärung, aus der Jean Paul kommt. Die jüngere Aufklärungsforschung hat deutlich machen können, wie sehr die Spätaufklärung die verschiedensten Tendenzen, gerade auch magisch-hermetische, alchemistische Traditionen der Naturphilosophie, in sich aufgenommen hat. (22) Vermutlich akzentuiert man jedoch falsch, wenn man den Eklektizismus der Spätaufklärung zu entschieden als strategisch gesteuerte Diskursbildung begreift. Denn Eklektizismus ist die lebenspraktisch notwendige Form der Partizipation an verschiedenen, sich überlagernden Diskursen. Wir verhalten uns heute doch nicht anders: Wir partizipieren an vielen Diskursen, je nachdem was wir brauchen und was wir in unseren Horizont integrieren können. Daß manche wissenschaftliche Forschung seltsam steril erscheinen kann, liegt nicht zuletzt auch daran - Paul Feyerabend hat immer wieder darauf hingewiesen -, daß sie streng und methodisch kontrolliert nur einer Diskurslinie zu folgen beansprucht. Mit den für Aufklärung einerseits, Romantik andererseits basalen ästhetischen Kategorien von Witz und Ironie situiert sich Jean Paul genau und bewußt zwischen den Diskursen als ein ständiger und nicht festlegbarer Grenzgänger zwischen Poesie und Ästhetik bzw. Poetik.

2. Selbstbehauptung durch Unverständlichkeit: Der Roman ist im 18. Jahrhundert noch eine, ja vielleicht die experimentelle literarische Gattung, wie Sternes Tristram Shandy, dem Jean Paul viel verdankt, Goethes Werther oder Hölderlins Hyperion zeigen. Bei Jean Paul unterscheidet sich die Schreibweise seines wichtigsten diskursiven Textes, der Vorschule der Ästhetik, aber nicht grundsätzlich von der seiner Romane. Man kann also für seinen literarischen Manierismus nicht in Anspruch nehmen und inn allein daraus begründen, daß der Roman noch eine experimentelle Gattung sei und solche Lizenzen erlaube. Es geht, scheint mir, bei Jean Paul nicht primär um eine Positionsbestimmung des Romans im literarischen Gattungssystem, sondern um eine Positionsbestimmung in einem viel weiteren Sinne. Der Beginn des VII. Programms der Vorschule der Ästhetik, in dem es um den Humor geht, macht schlagend deutlich, was ich meine, wenn ich Jean Pauls Manierismus als Selbstbehauptung durch Unverständlichkeit zu beschreiben suche:

Der Verstand und die Objekten-Welt kennen nur Endlichkeit. Hier finden wir nur jenen unendlichen Kontrast zwischen den Ideen (der Vernunft) und der ganzen Endlichkeit selber. Wie aber, wenn man eben diese Endlichkeit als subjektiven Kontrast jetzo der Idee (Unendlichkeit) als objektivem unterschöbe und liehe und statt des Erhabenen als eines angewandten Unendlichen jetzo ein auf das Unendliche angewandte Endliche, also bloß Unendlichkeit des Kontrastes gebäre, d. h. eine negative? Dann hätten wir den humour oder das romantische Komische. 
Und so ists in der Tat; und der Verstand, obwohl der Gottesleugner einer beschlossenen Unendlichkeit, muß hier einen ins Unendliche gehenden Kontrast antreffen. (23)

Dagegen ist Hegels Bestimmung des Humors geradezu meisterhaft klar. Jean Paul nimmt den

philosophisch-ästhetischen Diskurs in seiner schwierigsten Diktion auf und treibt ihn bis zur

Unverständlichkeit als einer besonderen Form der Überbietung.

Humor ist auch bei Jean Paul eine Kategorie der > Versöhnung < und Vermittlung des Gegenstrebigen und der >Totalität<. Jean Paul nimmt zum einen den zentralen Begriff der Autonomieästhetik auf - den der sTotalität < - zum andern die berühmte romantische Bestimmung der Poesie und grenzt sich von beiden ab: »Wenn Schlegel mit Recht behauptet, daß das Romantische nicht eine Gattung der Poesie, sondern diese selber immer jenes sein müsse: so gilt dasselbe noch mehr vom Komischen; nämlich alles muß romantisch, d. h. humoristisch werden. «(24) So eröffnet der Humor bei Jean Paul alle poetischen Lizenzen, wenn er nur »die Seele erwärmt« und der Leser eine »gewisse Vertraulichkeit« mitbringt und »einige Liebe, wenigstens keinen Haß gegen das schreibende Ich«. (25) Die Liebe ist auch bei Jean Paul (ähnlich bei Hölderlin und Jacobi) das versöhnende Prinzip des Gegenstrebigen und eklektisch Unvereinbaren, das es in seiner Disparatheit beläßt. Der Manierismus Jean Pauls ist empfindsam abgefedert. Es triumphiert nicht die agutezza. Manierismus in der höfischen Kultur und Manierismus in der Empfindsamkeitskultur des 18. Jahrhunderts sind nicht dasselbe. Im Geflecht der Diskurse sind die Werte des emotionalen Nahbereichs für Jean Paul das Regulativ, nicht die Vernunftideen.

3. Der darstellerische Gestus Jean Pauls ist der einer Subjektivität ohne Subjekt. Das ist natürlich eine paradoxe, theoretisch unhaltbare Formel, die hier nur helfen soll, Jean Pauls ästhetischen Gestus zu charakterisieren. Das Problem der Subjektivität ist für den philosophischen Diskurs um 1800 zentral. Die ästhetische Anmutung der Texte Jean Pauls ist die subjektiver Willkürlichkeit und völliger darstellerischer Freiheit: eben dies, was man schon in der Renaissance forcierter maniera vorgeworfen hatte. Deshalb ist es außerordentlich schwer, Jean Paul auf eine Position festzulegen. Systematisch wird die Position verunklärt, von der aus gesprochen wird. Vielfalt und Fülle geben den Maßstab ab. Manierismus ist eine Ästhetik des Lebens, die alle Schulästhetik ablehnt. (26) Eine grundsätzliche Humilitas, jedoch ohne erkennbare rhetorische Intentionalität, ist die zentrale rhetorisch-ästhetische Figur:

Was bleibt aber den jetzigen Menschen nach dem allgemeinen Verluste des Himmels bei einer hinzutretenden Einbuße der Erde? - Was dem auf dem Glanz-Schwanz eines poetischen Kometen nachschwimmenden Schreiber, wenn ihm der Kometen-Kern der Wirklichkeit plötzlich zermalmt wird? Er ist dann ohne Halt des Lebens, oder wie das Volk sich richtig ausdrückt, nicht mehr bei Troste.

Dieser Trost-Defekt offenbart sich schon im allgemeinen Streben, lieber etwas Lustiges als etwas Rührendes zu lesen - welches letzte allemal verdrüßlich fällt bei den entweder durch Schicksal oder durch Unglauben verlornen Realitäten. - Die letzte Fluchthöhle des aus einer festen Brusthöhle vertriebnen Herzens ist das Zwerchfell; es gibt ein Lachen des Zweifelns wie des Verzweifelns. Allein wo wird im ganzen mehr gelacht als in einer Irrenanstalt? (27)

Auch hier argumentiert Jean Paul selbstreflexiv: Seine Schreibweise ist inm Ausdruck einer kulturellen Situation und Reaktion auf sie. sUnregelmäßigkeit‘ ist Kennzeichen der Romantik, also der ästhetischen Moderne. (28) Das Werk muß sich nicht »ründen«, wie der zentrale Theoretiker der Autonomie-Ästhetik, Karl Philipp Moritz, fordert. Diagnosen, im Abend einer Epoche zu stehen, finden sich gerade in der Vorschule mehrfach. Die Antike war die Zeit der »Vollkommenheit«, die Moderne - »unsere kritischen Tage « - ist eine »kranke Zeit«, (29) geprägt von der »Willkür des jetzigen Zeitgeistes - der lieber ichsüchtig die Welt und das All vernichtet, um sich nur im freien Spiel-Raum im Nichts auszuleeren«, der »Willkür der Ichsucht«. (30)

So erscheint die Selbstreflexivität manieristischen Schreibens bei Jean Paul zugleich als kulturelle Reflexivität. Das, was die Manierismus-Forschung kulturkritisch an manieristischer Kunst betont hat, sie sei eine Erscheinung kulturellen Niedergangs, wird vom Manieristen Jean Paul selbst in Anspruch genommen. Der manieristische Roman, der eine eigene Welt schafft »nach dem allgemeinen Verluste des Himmels bei einer hinzutretenden Einbuße der Erde«, wird zum melancholischen Trostbüchlein für die der Transzendenz beraubte Seele. »Wo einer Zeit Gott, wie die Sonne, untergehet; da tritt bald darauf auch die Welt in das Dunkel«. (31) Dieses >nihilistische Experiment` (Kurt Wölfel) hat Jean Paul durchgespielt. Aus inm bezieht er seine Emphase für die Poesie. Jean Paul steht am Beginn einer neuen therapeutischen Besetzung von Literatur, und zwar gerade der in diesem Sinne nun tatsächlich autonom gewordenen Literatur.

Subjektivität ohne Subjekt soll deshalb auch heißen: Das Subjekt schreibt ohne ein erkennbares, es ganz und gar übersteigendes Gegenüber, von dem aus es sich definieren könnte durch Unterscheidung und durch das es definiert würde. So beginnt es zu reden, mit sich selbst und den andern, den Lesern und Kritikern, denen es eigentlich nicht anders ergeht. Es ist auf das Gespräch verwiesen, in dem es sich erst 
- und stets neu - konstitutiert, »da der Verfasser dieses «, so Jean Paul in der Vorrede zur ersten Auflage der Vorschule der Ästhetik, »lieber für jedes Du parteiisch sein will als für ein Ich«. (32) - Das ist ein Grundlagenproblem der Epoche, etwa bei Hölderlin, Fichte, Jacobi, auf die sich Jean Paul in der Vorschule auch bezieht. Eklektizismus und Synkretismus seines Manierismus eröffnen ein kommunikatives und prozessuales Verständnis von Kunst. Ich komme damit noch ganz kurz zu einer letzten Überlegung: 4. Gespräch und Selbstgespräch: Rüdiger Zymner hat gezeigt, wie sehr die manieristische Kunst und Schreibweise als eine Herausforderung an den Betrachter bzw. Leser zu verstehen ist. Sie provoziert ihn durch ihre Artistik der Darstellung zu einer Reaktion, auf eben diese Artistik selbst aufmerksam zu werden. Ich stimme dem völlig zu und möchte nur ergänzen, daß dies für alle herausfordernde Darstellung gilt, nicht nur in der Kunst, sondern auch im sozialen Leben.

An der Bedeutung des ästhetisch-sozialen Modells des Gesprächs wird die Bedeutung der ästhetischen Pragmatik für Jean Paul vielleicht am deutlichsten. Im Unterschied aber zur aufklärerischen Geselligkeitskonzeption und zum hermeneutischen Modell des Gesprächs in der frühen Hermeneutik geht es Jean Paul nicht primär um ein emphatisches, wechselseitiges Sich-Verstehen, sondern um die Gemeinsamkeit im Vollzug und Nachvollzug des ästhetischen Vergnügens. Nie darf das ästhetische »Scheinen « des Autors in seinem Werk »zum Sein « gemacht werden. (33) Die Vorrede zur zweiten Auflage des Hesperus ist ein fortwährendes Selbstgespräch des Autors, der seinen »Entwurf der gegenwärtigen Vorrede « in einem Wechsel von Selbstzitat und Kommentar präsentiert. Dieser Entwurf enthält Anweisungen, wie eine richtige Vorrede auszusehen habe: »Mache sie aber kurz, da der Welt der Gang durch zwei Vorzimmer in die Passagierstube des Buchs ohne hin lang wird - Scherz' anfangs Selten schiebt einer auf der literarischen Kegelbahn alle neun Musen - Der Schluß aus der Reflexion Bringe viele Ähnlichkeiten zwischen dem Titel Hesperus und dem Abendsterne oder der Venus heraus, [...] - Sei ein Fuchs und streichle die kritischen Billard-Markörs, welche Verlust und Gewinn ansagen.« (34) Jean Paul ruft sich die rhetorische brevitas in Erinnerung und den Topos ex nomine, um schließlich zu bekennen: »Letztes «, also die letzte Anweisung an sich selbst, »versteh' ich selber nicht, weil der Entwurf schon im Winter geschrieben wurde.« (35) Poetische Rede ist zugleich immer poetische Rede über poetische Rede. Manierismus wird so zum autokommunikativen Akt in Permanenz. So gesehen, hätte die Moderne eine grundsätzliche Tendenz zum Manierismus.

\section{Fußnoten:}

1. Rüdiger Zymner: Manierismus. Zur poetischen Artistik bei Johann Fischart, Jean Paul und Arno Schmidt, Paderborn - München - Wien - Zürich 1995, hier S. 256 und 257.

2. Dies war auch der leitende Gedanke der von Christine Göttler und mir geleiteten Tagung >Manier und Manierismus<, die vom 24. - 26. April 1998 im Zentrum für interdisziplinäre Forschung stattgefunden hat. Das Folgende ist der Text meines dort gehaltenen Vortrags; die Vortragsform wurde beibehalten.

3. Brief an Emanuel Osmund, 3. August 1818; zit. nach dem Kommentar: Jean Paul: Sämtliche Werke. Abt. I. Bd. 6. Herausgegeben von Norbert Miller, 2. Aufl. München 1996, S. 1312 (im folgenden zitiert als SW Abt., Bd., S.).

4. SW I, 6, S. 1039.

5. Hanns Bächthold-Stäubli: Handwörterbuch des deutschen Aberglaubens. Bd. 8, Berlin / Leipzig 1927 1942 (Repr. 1987), Sp. 1681.

6. Kommentar, SW I, 6, S. 1277.

7. Ebd., S. 1039.

8. Ebd.

9. Friedrich Schiller: Über Bürgers Gedichte. In: Schillers Werke. Nationalausgabe. 22. Bd. Vermischte Schriften. Hg. von Herbert Meyer, Weimar 21991, S. 245 - 264, hier S. 246: »Alles, was der Dichter uns geben kann, ist seine Individualität. Diese muß es also wert sein, vor Welt und Nachwelt ausgestellt zu werden. Diese seine Individualität so sehr als möglich zu veredeln, zur reinsten herrlichsten Menschheit hinaufzuläutern, ist sein erstes und wichtigstes Geschäft, ehe er es unternehmen darf, die Vortrefflichen zu rühren.«

10. Knapp und zusammenfassend: Gert Ueding / Bernd Steinbrink: Grundriß der Rhetorik. Geschichte Technik - Methode, Stuttgart / Weimar ${ }^{4}$ 1994, S. 26 ff. - Cicero und Schiller in einem Atemzug zu nennen, mag etwas sprunghaft scheinen. Man muß aber auch Schiller von der rhetorischen Tradition her sehen, wie vor allem Klaus Dockhorn gezeigt hat: Macht und Wirkung der Rhetorik. Vier Beiträge zur Ideengeschichte der Vormoderne, Bad Homburg 1968. 
11. Peter Schwind: Schwulst-Stil. Historische Grundlagen von Produktion und Rezeption manieristischer Sprachformen in Deutschland 1624 - 1738, Bonn 1977 (Abhandlungen zur Kunst-, Musik- und Literaturwissenschaft, Bd. 231).

12. Eine Frage sei hier kurz angeschnitten: die nach der Übernahme des ursprünglich kunstwissenschaftlichen Begriffs des Manierismus in die Musik- und Literaturwissenschaften. Diese Frage schließt die allgemeinere ein, warum überhaupt kunsthistorische Begriffe (wie z. B. der des Expressionismus) von anderen Disziplinen übernommen werden. Mir scheint, daß hier die Evidenz des Anschaulichen für die von ihrer semiotischen Verfaßtheit her unanschaulichen Disziplinen in Anspruch genommen wird. Manierismus konnotiert zudem stärker Individualität als der auch schon im 16. Jahrhundert vorkommende Begriff des Schwulstes, der also stärker auf das rhetorische Phänomen abhebt. Schwulstkritik ist stärker Sprachkritik; Manierismuskritik ist aber eher Kulturkritik.

13. Vgl. Volker Ulrich Müller: Narrenfreiheit und Selbstbehauptung. Spielräume des Humors im Werk Jean Pauls, Stuttgart 1979. Müller geht es jedoch um die geistesgeschichtliche Einordnung Jean Pauls zwischen Aufklärung, aus der er komme, und subjektivem Idealismus, dem er tatsächlich schon angehöre.

14. Vgl. die ausgezeichnete, sich theoretisch auf Bachtin stützende und am >Siebenkäs< entwickelte Untersuchung von Hans Esselborn: Die Vielfalt der Redeweisen und Stimmen. Jean Pauls erzählerische Modernität. In: Jahrbuch der Jean-Paul-Gesellschaft 26 / 27, 1991 / 1992, S. 32 - 66.

15. Eindrucksvoll ist in dieser Hinsicht auch die Analyse von Hendrik Birus: Vergleichung. Goethes Einführung in die Schreibweise Jean Pauls, Stuttgart 1986. Birus untersucht Goethes letzte, knappe Bemerkung über Jean Paul im West-östlichen Divan (1819), die nun Jean Pauls spezifischer Schreibweise gerechter zu werden versucht. Schon 1814 äußert sich Goethe in einem Brief an Knebel (16.3.1814) zu einem Auszug im Morgenblatt aus der zweiten Auflage der Levana in Worten, die Jean Pauls Stil jetzt geradezu als Abkehr von allen manieristischen Tendenzen erscheinen lassen: »Eine unglaubliche Reife ist darin zu bewundern. Hier erscheinen seine kühnsten Tugenden, ohne_die mindeste Ausartung, große und richtige Umsicht, faßlicher Gang des Vortrags, Reichtum von Gleichnissen und Anspielungen, natürlich fließend, ungesucht, treffend und gehörig und das alles in dem gemütlichsten Elemente. Ich weiß nichts Gutes genug von diesen wenigen Blättern zu sagen und erwarte die neue Levana mit Vergnügen. «Zit. nach Peter Sprengel (Hg.): Jean Paul im Urteil seiner Kritiker. Dokumente zur Wirkungsgeschichte Jean Pauls in Deutschland, München 1980, S. 342; Hervorhebungen von mir. Ebd., S. 97 f., wird Goethes $>$ Vergleichung < abgedruckt. Es springt ins Auge, wie Goethe in dieser Bemerkung einige der Topoi zitiert, die auch in der Bewertung des Manierismus bis heute wichtig sind. Der späte Jean Paul erscheint hier als geheilt vom Manierismus seiner frühen Jahre. Aber hat sich Goethe nicht selbst von seinem Klassizismus der neunziger Jahre gelöst, der ihn Jean Paul noch harsch kritisieren ließ? Zum Verhältnis Goethes zu Jean Paul vgl. auch die Einleitung Sprengels, ebd., bes. S. XXVIII ff.

16. SW I, Bd. 1, S. 483; Hervorhebung von mir. Auf diese Stelle geht auch Sprengel, Einleitung (s. Anm. 14), ein.

17. SW I, 1, S. 484; vgl. überhaupt die Überschrift zum Entwurf der Vorrede, ebd., S. 481: »Architektonik und Bauholz für die Vorrede zur zweiten Auflage des Hesperus«.

18. Ebd.

19. Dazu Hans-Georg Pott: Jean Paul und die Moderne. In: Jahrbuch der Jean-Paul-Gesellschaft 26 / 27, 1991 / 92, S. $17-31$.

20. Vgl. Friedrich Schlegel: Brief über den Roman; der einschlägige Auszug ist abgedruckt bei Sprengel (Hg.), Jean Paul im Urteil seiner Kritiker (s. Anm. 14), S. 32 - 35.

21. Das ist eine wichtige Perspektive des Nachworts Ralph-Rainer Wuthenows zur Reclam-Ausgabe der Selberlebensbeschreibung, Stuttgart 1977 (UB 7940).

22. Hans Blumenberg: Die Lesbarkeit der Welt, Frankfurt a. M. 1981.

23. Vgl. etwa Hans-Georg Kemper: Gottebenbildlichkeit und Naturnachahmung im Säkularisierungsprozeß. Problemgeschichtliche Studien zur deutschen Lyrik in Barock und Aufklärung. 2 Bde., Tübingen 1981 (Studien zur deutschen Literatur, Bd. 64 u. 65).

24. SW I, 5, S. $124 \mathrm{f}$.

25. Ebd., S. 127.

26. Ebd., S. 129, 133.

27. Vgl. ebd., S. $400 \mathrm{f}$.

28. Ebd., S. 401.

29. Ebd., S. 87.

30. Ebd., S. 25.

31. Ebd., S. 31.

32. Ebd.

33. Ebd., S. 26.

34. Ebd., S. 133.

35. SW I, 1, S. 481.

36. Ebd. 